\title{
INHIBITION EFFECT OF SOME COMMERCIAL CORROSION INHIBITORS ON MILD STEEL IN 7.0 M PHOSPHORIC ACID
}

\author{
JULIETA DANIELA CHELARU ${ }^{a}$, MIHAELA CIOBRA ${ }^{a}$ AND \\ LIANA MARIA MUREŞAN ${ }^{\mathrm{a}, *}$
}

\begin{abstract}
Corrosion tests were carried out in order to find the best inhibitor for the protection of steel pipelines used in $\mathrm{H}_{3} \mathrm{PO}_{4}$ and fertilizers industry. The corrosion inhibition efficiency of five commercial inhibitors was investigated on mild steel by using electrochemical methods (EIS and polarization curves) in a $7 \mathrm{M} \mathrm{H}_{3} \mathrm{PO}_{4}$ solution ( $\mathrm{pH} 0.5$ ). The efficiency of best corrosion inhibitors was tested at different concentrations.
\end{abstract}

Key words: mild steel, corrosion inhibitors, electrochemical impedance spectroscopy, polarization curves, inhibitor efficiency, phosphoric acid.

\section{INTRODUCTION}

Phosphoric acid is widely used in the production of fertilizers and surface treatment of steel such as surface cleaning, chemical and electrolytic polishing, coloring, etching, removal of oxide film, phosphating and passivating [1]. Most of the acid is produced from phosphate rocks by the so-called dihydrate wet process, equivalent to $7.0 \mathrm{M} \mathrm{H}_{3} \mathrm{PO}_{4}$ (about $35 \% \mathrm{H}_{3} \mathrm{PO}_{4}$ ) [2]. Most of the industrial equipment is made of steel that can be damaged by the contact with this acidic solution; this is why it is imperative to protect the steel materials used in the phosphoric acid industry.

The use of inhibitors is one of the most practical methods for protecting metals or alloys from corrosion [3]. There is a wide variety of organic compounds used as corrosion inhibitors for steel in $\mathrm{H}_{3} \mathrm{PO}_{4}$ media: thiosemicarbazones [4], hydroxyquinoline derivatives [5], triazole derivatives [6 - 8], imidazoles [9], tetraalkylammonium salts [10], "green compounds" such as plant extracts [11 13], guar gum [14] etc., but to find new efficient corrosion inhibitors remains of major interest.

a "Babeş-Bolyai" University, Faculty of Chemistry and Chemical Engineering, Department of Chemical Engineering, 11 Arany Janos St., 400028 Cluj-Napoca, Romania

*Corresponding author: limur@chem.ubbcluj.ro 
In this context, the aim of this paper is to investigate the corrosion of mild steel in $7.0 \mathrm{M} \mathrm{H}_{3} \mathrm{PO}_{4}$ solution ( $\mathrm{pH} 0.5$ ) in the absence and in the presence of three commercial products from Nalco Products, USA, (3DT177, 3DT179, Nalco 73413). The effect of these inhibitors was compared with that of Galoryl IC20 (produced by ArrMazz Chemicals SAS, USA) and Corrogard (Able Westchem, Australia). The protective effect of inhibitors at different concentrations was investigated by electrochemical methods (polarization measurements and electrochemical impedance spectroscopy).

\section{RESULTS AND DISCUSSION}

\section{Open circuit potential}

In order to determine the corrosion behavior of carbon steel in corrosive media $7 \mathrm{M} \mathrm{H}_{3} \mathrm{PO}_{4}(\mathrm{pH}=0.5)$ in the absence and in the presence of corrosion inhibitors, the experiments were started by recording the open circuit potential (OCP) of the samples in time. The OCP values were situated between $-0.370 \mathrm{~V}$ and $-0.410 \mathrm{~V}$ vs. $\mathrm{Ag} / \mathrm{AgCl} / \mathrm{KCl}_{\text {sat }}$ and become relatively constant after $1 \mathrm{~h}$.

\section{Electrochemical impedance spectroscopy}

Nyquist impedance spectra were recorded immediatly after OCP monitoring in the corrosive solution $(\mathrm{pH} 0.5)$ in the presence of inhibitors and the obtained results were compared with those without inhibitors (Figure 1). In all cases, a pure capacitive behavior of the systems was noticed. The electrical equivalent circuit used to fit the experimental spectra was $R_{e}\left(Q R_{p}\right)$, where $R_{e}$ is the corrosion solution resistance and the couple $Q-R_{p}$, represents the constant phase element corresponding to the double layer capacity and the polarization resistance, respectively. The polarization resistance corresponds to the corrosion reaction at the metal substrate / solution interface, which contains charge transfer resistance, double layer resistance, film resistance and other accumulations at the metal / solution interface [15]. As the main contribution is that of the charge transfer resistance, we assumed that $R_{p}$ in our case can be practically assimilated to the charge transfer resistance, $R_{c t}$. The values of $C_{d l}$ were calculated using the equation $C_{d l}=\left(R^{1-n} Q\right)^{1 / n}$, where $n$ reflects the depressed feature of the capacitive loop in Nyquist diagram $(0<n \leq 1)$ which is generally attributed to the frequency dispersion, as well as to inhomogeneities, roughness of metal surface and mass transport process [16]. The obtained results for all the analysed samples are presented in Table 1 . The chi squared $\left(x^{2}\right)$ values were of order $10^{-4}$. 
Analyzing the Table 1 data it can observed that in the case of using $0.2 \mathrm{~mL} / \mathrm{L}$ of inhibitors, an increase of the charge transfer resistance, $R_{c t}$, can be noticed, but this increase is not significant. Best results were obtained in the case of Corrogard and Nalco 73413.

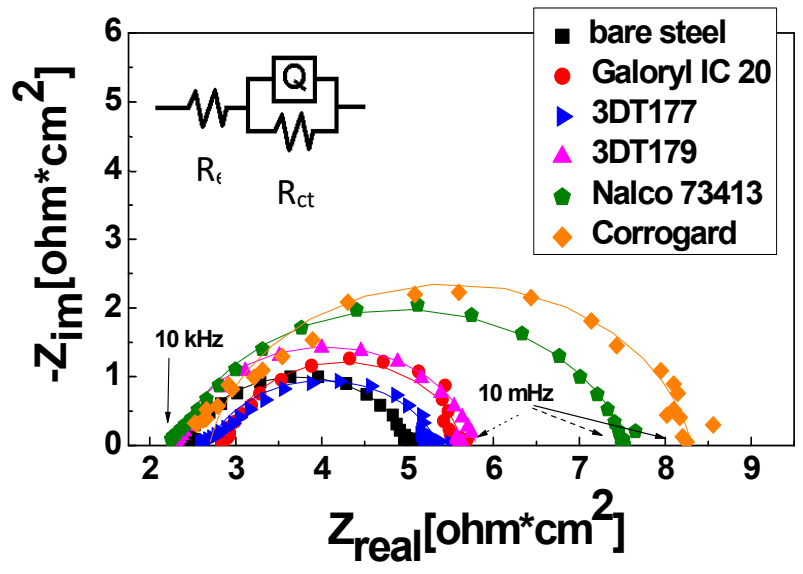

Figure 1. Nyquist impedance diagrams for the steel electrodes recorded in $7 \mathrm{M}$ $\mathrm{H}_{3} \mathrm{PO}_{4}$ solution ( $\left.\mathrm{pH} 0.5\right)$, in the absence and in the presence of corrosion inhibitors $(c=0.2 \mathrm{~mL} / \mathrm{L})$ after $1 \mathrm{~h}$ at OCP; the lines represent fitted data

Table 1. The electrochemical impedance parameters estimated by fitting the experimental impedance data from Figure 1.

\begin{tabular}{|l|c|c|c|c|}
\hline Inhibitors & $\begin{array}{c}\mathbf{R e} \\
{\left[\mathbf{\Omega}^{*} \mathbf{c m}^{2}\right]}\end{array}$ & $\begin{array}{c}\mathbf{R}_{\mathbf{c t}^{\mathbf{a}}} \\
{\left[\mathbf{\Omega}^{*} \mathbf{c m}^{2}\right]}\end{array}$ & $\begin{array}{c}\mathbf{C}_{\mathbf{d i l}^{\mathbf{b}}} \\
{\left[\mathbf{m F} / \mathbf{c m}^{\mathbf{2}}\right]}\end{array}$ & $\mathbf{n}_{\mathbf{d l l}^{\mathbf{c}}}$ \\
\hline No inhibitors & 2.42 & 2.596 & 1.211 & 0.836 \\
\hline 3DT177 & 2.25 & 3.387 & 0.790 & 0.878 \\
\hline 3DT179 & 2.88 & 2.742 & 0.946 & 0.924 \\
\hline Galoryl IC20 & 2.67 & 2.686 & 1.033 & 0.781 \\
\hline Corrogard & 2.69 & 5.612 & 0.591 & 0.888 \\
\hline Nalco 73413 & 2.29 & 5.267 & 0.679 & 0.821 \\
\hline
\end{tabular}

aThe standard error for $R_{c t}$ values was between $0.77 \%-2.16 \%$; ${ }^{b}$ The standard error for $Q$ values was between $2.34 \%-5.42 \%$; ${ }^{c}$ The standard error for $n_{d l}$ values was between $1.02 \%-2.27 \%$

Next, in an attempt to optimize the results, the inhibitors with the best inhibition efficiencies (Corrogard and Nalco 73413) were tested at different concentrations. As before, the experiments started with the measurement of the open-circuit potential (OCP) of the steel electrodes for a period of 1 hour, followed by the recording of EIS spectra. 
Figure 2 shows the Nyquist plots obtained for all analyzed steel samples, in the presence of Corrogard and Nalco 73413 at concentrations of $0.2 \mathrm{~mL} / \mathrm{L}, 0.4 \mathrm{~mL} / \mathrm{L}, 0.6 \mathrm{~mL} / \mathrm{L}$ and $0.8 \mathrm{~mL} / \mathrm{L}$. All the plots contain depressed semicircles reflecting a pure capacitive behavior. The results obtained both in the absence and in the presence of inhibitors can be suitably represented by using only one time constant circuit and the parameters obtained for all samples are shown in Table 2.
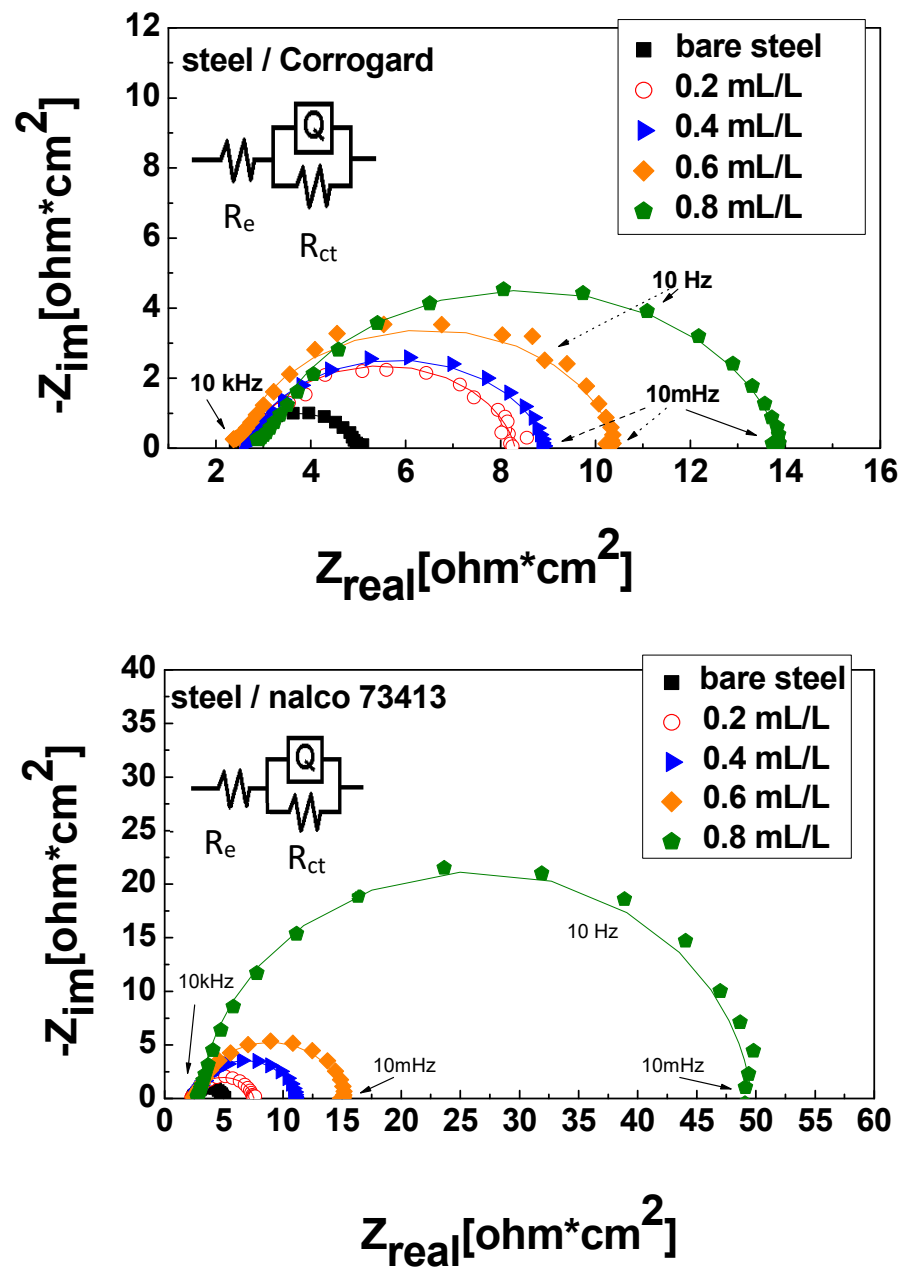

Figure 2. Nyquist impedance diagrams for the steel electrodes in $7 \mathrm{M} \mathrm{H}_{3} \mathrm{PO}_{4}$ solution ( $\mathrm{pH}$ 0.5), in the presence of the corrosion inhibitors Corrogard and Nalco 73413 at different concentrations; the lines represent fitted data 
INHIBITION EFFECT OF SOME COMMERCIAL CORROSION INHIBITORS ON MILD STEEL IN 7.0 M PHOSPHORIC ACID

Table 2. The electrochemical impedance parameters estimated by fitting the experimental impedance data from Figure 2.

\begin{tabular}{|c|c|c|c|c|c|}
\hline Inhibitors & $\begin{array}{c}\mathbf{C}_{\text {inh }} \\
{[\mathbf{m L} / \mathbf{L}]}\end{array}$ & $\begin{array}{c}\mathbf{R}_{\mathbf{e}} \\
{\left[\mathbf{\Omega}^{*} \mathbf{c m}^{2}\right]}\end{array}$ & $\begin{array}{c}\mathbf{R}_{\mathbf{c t}} \\
{\left[\mathbf{\Omega}^{*} \mathbf{c m}^{2}\right]}\end{array}$ & $\begin{array}{c}\mathbf{C}_{\text {dl }} \\
{\left[\mathbf{m F} / \mathbf{c m}^{2}\right]}\end{array}$ & $\mathbf{n}_{\text {dll }}$ \\
\hline \multirow{4}{*}{ Corrogard } & 0 & 2.42 & 2.596 & 1.211 & 0.837 \\
\hline \multirow{4}{*}{ Nalco 73413 } & 0.2 & 2.69 & 5.612 & 0.591 & 0.889 \\
\cline { 2 - 6 } & 0.4 & 2.63 & 6.345 & 0.588 & 0.855 \\
\cline { 2 - 6 } & 0.6 & 2.48 & 7.937 & 0.565 & 0.899 \\
\cline { 2 - 6 } & 0.8 & 2.99 & 10.92 & 0.544 & 0.878 \\
\cline { 2 - 6 } & 0.2 & 2.29 & 5.267 & 0.717 & 0.872 \\
\cline { 2 - 6 } & 0.4 & 2.50 & 8.524 & 0.679 & 0.886 \\
\cline { 2 - 6 } & 0.6 & 2.47 & 12.85 & 0.576 & 0.864 \\
\hline
\end{tabular}

a The standard error for $R_{c t}$ values was between $1.41 \%-2.75 \%$; ${ }^{b}$ The standard error for $Q$ values was between $3.39 \%-5.61 \%$; ${ }^{c}$ The standard error for $n_{d l}$ values was between $0.97 \%-1.53 \%$

From the data presented in Table 2, it can be concluded that, as expected, the protective effect of the inhibitors depends on their concentration and generally, the corrosion resistance slightly improved as their concentration increased.

\section{Polarization measurements}

To determine the polarization resistance of the electrodes, linear polarization curves were recorded, in the potential domain of $\pm 20 \mathrm{mV} v s$. OCP. The polarization resistance $\left(R_{p}\right)$ values, for each electrode, was calculated with the formula: $R_{p(\Delta E \rightarrow 0)}=\frac{\Delta E}{\Delta i}$, (1), and are shown in Table 4. The protection efficiency of the inhibitors on steel was determined either with the formula: $I E[\%]=\frac{R_{p}^{i n h}-R_{p}^{0}}{R_{p}^{i n h}} \cdot 100,(2)$, where $\mathrm{R}_{\mathrm{p}}$ inh and $\mathrm{R}_{\mathrm{p}}{ }^{0}$ are the polarization resistances in presence and in the absence of inhibitors, respectively, or with the formula , $I E[\%]=\frac{i^{0}-i^{i n h}}{i^{0}} \cdot 100(3)$, where $\mathrm{i}^{\text {inh }}$ and $\mathrm{i}^{0}$ are the corrosion current densities in presence and in the absence of inhibitors, respectively.

In order to determine the kinetic parameters of the corrosion process, potentiodynamic polarization curves were recorded in the potential range of $\pm 200 \mathrm{mV}$ vs. OCP (Figure 3), after OCP recording during $1 \mathrm{~h}$. The Tafel interpretation of the polarization curves provided the results presented in Table 3. 


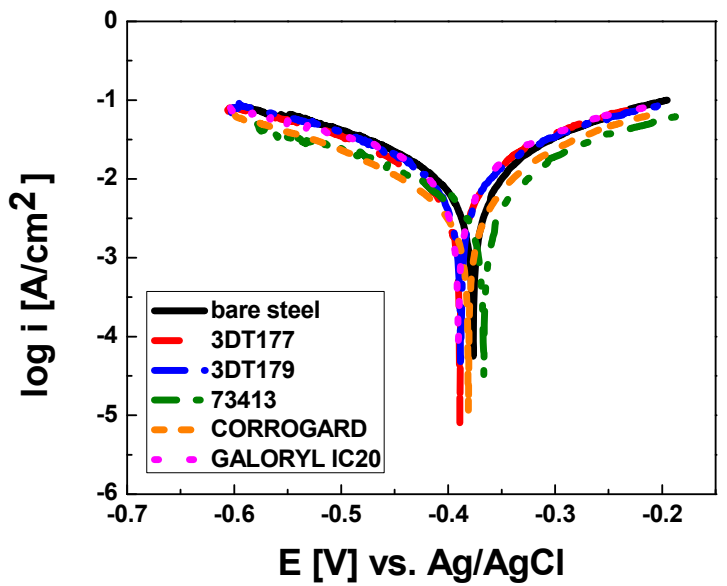

Figure 3. The polarization curves ( $\pm 200 \mathrm{mV} v s$. OCP) for the steel immersed in $7 \mathrm{M} \mathrm{H}_{3} \mathrm{PO}_{4}(\mathrm{pH}=0.5)$ at $0.2 \mathrm{~mL} / \mathrm{L}$ concentration of inhibitors; scan rate, $10 \mathrm{mV} / \mathrm{min}$.

Table 3. Corrosion process parameters in the absence and in the presence of the examined inhibitors at $0.2 \mathrm{~mL} / \mathrm{L}$ concentration.

\begin{tabular}{|l|c|c|c|c|c|c|}
\hline Inhibitors & $\begin{array}{c}\mathbf{O C P} \\
{[\mathbf{m V} \text { vs }} \\
\mathbf{R E}]\end{array}$ & $\begin{array}{c}\mathbf{E}_{\text {cor }} \\
{[\mathbf{m V} \text { vs }} \\
\mathbf{R E}]\end{array}$ & $\begin{array}{c}\mathbf{i}_{\text {cor }} \\
{\left[\mathbf{m A} / \mathbf{c m}^{2}\right]}\end{array}$ & $\begin{array}{c}\boldsymbol{\beta}_{\mathbf{a}} \\
{[\mathbf{m V / d e c}]}\end{array}$ & $\begin{array}{c}\boldsymbol{\beta}_{\mathbf{c}} \\
{[\mathbf{m V / d e c}]}\end{array}$ & $\begin{array}{c}\text { IE } \\
{[\%]}\end{array}$ \\
\hline Bare steel & -396 & -393 & 17.62 & 236 & 344 & - \\
\hline 3DT177 & -408 & -395 & 12.82 & 156 & 192 & 27.22 \\
\hline 3DT179 & -410 & -381 & 14.72 & 323 & 372 & 16.44 \\
\hline Galoryl IC20 & -439 & -391 & 15.74 & 217 & 201 & 10.66 \\
\hline Corrogard & -402 & -384 & 12.05 & 178 & 255 & 31.60 \\
\hline Nalco 73413 & -378 & -373 & 12.58 & 232 & 302 & 28.55 \\
\hline
\end{tabular}

$\beta_{\mathrm{a}}$ and $\beta_{\mathrm{c}}$ are the Tafel coefficients

The analysis of the data led to the conclusion that in the case of all tested corrosion inhibitors, a slight decrease of the corrosion current densities can be noticed, even if the inhibition efficiency (IE) was not satisfactory.

In an attempt to see if responsible for this situation was the concentration of the additives, the inhibitors with the highest inhibition efficiency (Corrogard and Nalco 73413) were tested at different concentrations: $0.2 \mathrm{~mL} / \mathrm{L}, 0.4 \mathrm{~mL} / \mathrm{L}, 0.6 \mathrm{~mL} / \mathrm{L}$ and $0.8 \mathrm{~mL} / \mathrm{L}$ and the corresponding polarization curves are presented in Figure 4. 

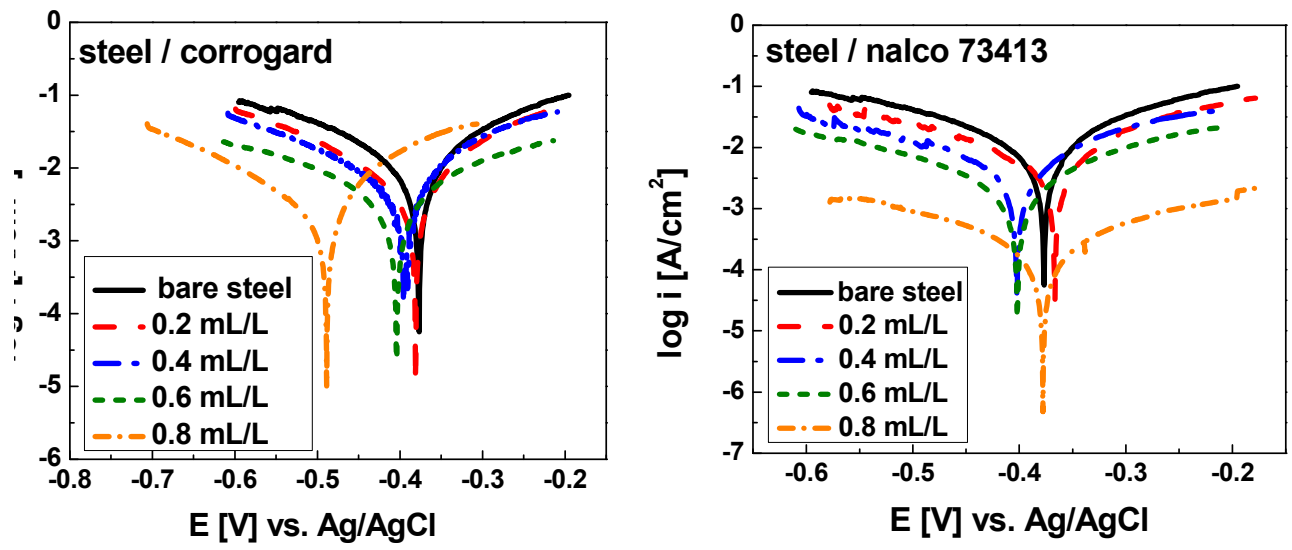

Figure 4. The polarization curves ( $\pm 200 \mathrm{mV}$ vs. OCP) for the $\mathrm{S} 235$ steel immersed in $7 \mathrm{M} \mathrm{H} 3 \mathrm{PO} 4(\mathrm{pH}=0.5)$ at different concentrations of inhibitors; scan rate, $10 \mathrm{mV} / \mathrm{min}$.

Both branches of the polarization curves are influenced by the inhibitors, proving that they act as mixed-type inhibitors. The Tafel interpretation of the polarization curves led to the results presented in Table 4.

Table 4. Kinetic parameters of the corrosion process in $7 \mathrm{M} \mathrm{H}_{3} \mathrm{PO}_{4}$ at different concentrations of inhibitors Corrogard (1) and Nalco 73413 (2)

\begin{tabular}{|c|c|c|c|c|c|c|c|c|c|}
\hline \multirow{2}{*}{ Inh } & \multirow{2}{*}{$\begin{array}{c}C_{\text {inh }} \\
{[\mathrm{mL} / \mathrm{L}]}\end{array}$} & \multirow{2}{*}{$\begin{array}{c}\text { OCP } \\
{[m V \text { vs }} \\
R E]\end{array}$} & \multirow{2}{*}{$\begin{array}{l}E_{\text {cor }} \\
m V \text { v } \\
R E]\end{array}$} & \multirow{2}{*}{$\begin{array}{c}\mathbf{i}_{\text {cor }} \\
{\left[\mathrm{mA} / \mathrm{cm}^{2}\right]}\end{array}$} & \multirow{2}{*}{$\begin{array}{c}\beta_{\mathrm{a}} \\
{[\mathrm{mV} / \mathrm{dec}]}\end{array}$} & \multirow{2}{*}{$\begin{array}{c}-\beta_{c} \\
{[\mathrm{mV} / \text { dec }]}\end{array}$} & \multirow{2}{*}{$\begin{array}{c}\mathbf{R}_{\mathbf{p}} \\
{\left[\mathbf{\Omega} \mathbf{c m}^{2}\right]}\end{array}$} & \multicolumn{2}{|c|}{ IE [\%] } \\
\hline & & & & & & & & $\mathbf{I}_{\text {cor }}$ & $\mathbf{R p}$ \\
\hline- & 0 & -396 & -393 & 17.62 & 236 & 344 & 6.73 & - & - \\
\hline \multirow{4}{*}{1} & 0.2 & -402 & -384 & 12.05 & 177 & 255 & 10.86 & 32.09 & 38.02 \\
\hline & 0.4 & -410 & -414 & 10.16 & 205 & 283 & 10.51 & 42.32 & 36.01 \\
\hline & 0.6 & -415 & -416 & 5.57 & 472 & 930 & 21.27 & 68.37 & 68.36 \\
\hline & 0.8 & -508 & -501 & 4.57 & 159 & 247 & 17.57 & 74.06 & 61.70 \\
\hline \multirow{4}{*}{2} & 0.2 & -378 & -373 & 12.58 & 232 & 302 & 11.11 & 28.55 & 38.77 \\
\hline & 0.4 & -408 & -404 & 10.14 & 351 & 628 & 13.51 & 42.46 & 49.66 \\
\hline & 0.6 & -409 & -408 & 4.21 & 281 & 380 & 25.25 & 76.07 & 73.47 \\
\hline & 0.8 & -378 & -375 & 0.44 & 424 & 420 & 284.09 & 97.45 & 97.63 \\
\hline
\end{tabular}

It can be observed, especially in the case of Nalco 73413, a significant increase of the inhibition efficiency in parallel with the inhibitors' concentration. The highest efficiency was noticed at $0.8 \mathrm{~mL} / \mathrm{L}$, when a decrease of the 
corrosion current density with two orders of magnitude was observed in comparison with the absence of the additive. The same trend was observed in the case of Corrogard, but its effect was not so important.

Both inhibitors act as mixed-type inhibitors. The inhibition effect comes from the reduction of the reaction area on the surface of the corroding metal after inhibitor adsorption [17]. The surface coverage $\theta$ of the electrode surface at different inhibitor concentrations, calculated from the equation $\theta=$ $\mathrm{IE} / 100$, suggests an incomplete coverage of the electrode surface with inhibitor molecules, which explains their moderate effect.

The beneficial effect of inhibitors was put in evidence also by visual inspection of the corroded surfaces of the electrodes (Figure 5). It can be observed that in case of bare steel, the corrosion products layer is not uniform, with severely corroded areas, while in the case of using corrosion inhibitors, the aspect of the samples is uniform and the presence of rust is not visible.

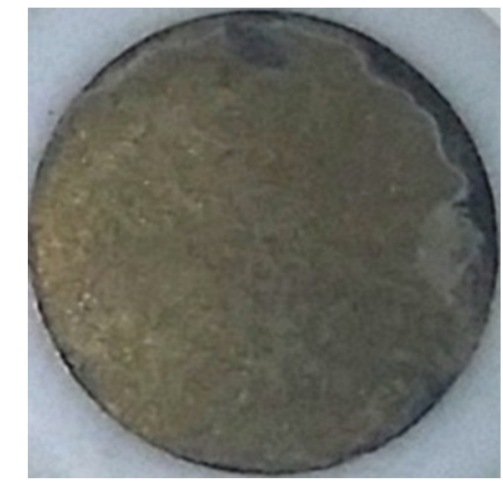

Bare steel

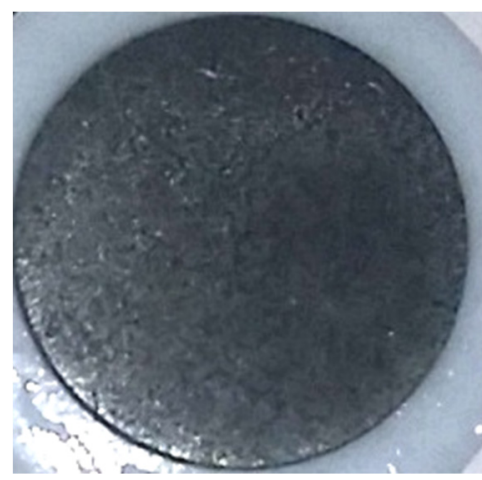

Corrogard

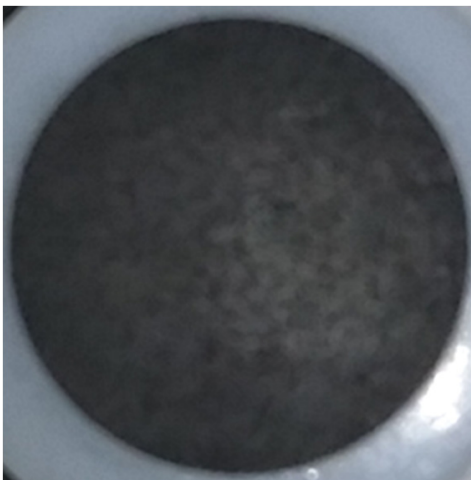

Nalco 37413

Figure 5. Influence of the inhibitors (c $=0.2 \mathrm{~mL} / \mathrm{L}$ ) on the aspect of the steel electrodes immersed in $7 \mathrm{M} \mathrm{H}_{3} \mathrm{PO}_{4}$ solution after corrosion tests 


\section{CONCLUSIONS}

In terms of practical use, based on electrochemical investigations, all inhibitors tested in the present work can be used as inhibitors against steel corrosion in concentrated phosphoric acid. The best was Nalco 37413.

The protective effect of the inhibitors is moderate, depends on their concentration and generally, the corrosion resistance improved as their concentration increased.

All investigated compounds act as a mixed-type inhibitor, and the inhibition is caused by geometric blocking effect of the surface. EIS spectra exhibit only one capacitive loop which indicates that the corrosion reaction is controlled by the charge transfer process.

Further investigations to assess the corrosion morphology and to elucidate the mechanism for the inhibition of mild steel corrosion in $7 \mathrm{M} \mathrm{H}_{3} \mathrm{PO}_{4}$ acidic media are required.

\section{EXPERIMENTAL}

\section{Materials and solutions}

The commercial inhibitors used in the experiments were Nalco 73413, two phosphino succinic oligomer derivatives (3DT177, 3DT179) from Nalco Products USA, and two other products, namely Galoryl IC20 (ArrMazz Chemicals SAS, USA) and Corrogard (Able Westchem, Australia). The inhibitors were dissolved in the corrosive solution at different concentrations: $0.2 \mathrm{~mL} / \mathrm{L}, 0.4 \mathrm{~mL} / \mathrm{L}, 0.6 \mathrm{~mL} / \mathrm{L}, 0.8 \mathrm{~mL} / \mathrm{L}$.

Mild steel samples $(0.22 \% \mathrm{C}, 0.85 \% \mathrm{Mn}, 0.055 \% \mathrm{P}, 0.055 \% \mathrm{~S}$ and Fe balance) were used in the experiments. The working electrodes - WE were cut from a steel bar $\left(S=0.5 \mathrm{~cm}^{2}\right)$ mounted in Teflon; a copper rod was attached for electrical contact.

Prior to electrochemical tests, the steel samples were ground using different emery papers up to 2000 grade, washed with distilled water and degreased with acetone, after that were dried at room temperature.

\section{Experimental methods}

The electrochemical corrosion measurements were performed on a PC - controlled electrochemical analyzer PAR 2273 (Princeton Applied Research, USA) using a three electrodes cell containing a working electrode (steel), a saturated $\mathrm{Ag} / \mathrm{AgCl} / \mathrm{KCl}$ electrode as reference electrode, and a 
platinum counter electrode. The electrolyte solution for corrosion measurements was acidic $7 \mathrm{M} \mathrm{H}_{3} \mathrm{PO}_{4}(\mathrm{pH}=0.5)$.

The open circuit potential for steel immersed in the corrosive solution was monitored during 1 hour. Then, electrochemical impedance spectroscopy spectra (EIS) were recorded in the frequency ranging from $10 \mathrm{kHz}-10 \mathrm{mHz}$ with a disturbance voltage of $\pm 10 \mathrm{mV}$ at 30 points/decade. The impedance data were fitted with a $R(Q R)$ equivalent electrical circuit, using the ZSimpWin V3.21 software.

After the EIS measurement was finished, polarization curves were recorded immediately by scanning in a potential range of $\pm 20 \mathrm{mV}$ (for polarization resistance determination) and of $\pm 200 \mathrm{mV} v$ s. open circuit potential, (for Tafel interpretation) with a scan rate of $10 \mathrm{mV} / \mathrm{min}$. The testing temperature was kept at $20^{\circ} \mathrm{C}$.

\section{REFERENCES}

1. X. Li, S. Deng, X. Xie, Arab. J. Chem., 2017, 10, 3715-3724.

2. Y. Jianguo, W. Lin, V. Otieno-Alego, D.P. Schweinsberg, Corros. Sci., 1995, 37, 975-985.

3. M. Finšgar, J. Jackson, Corros. Sci., 2014, 86, 17-41.

4. T. Poornima, J. Nayak, A. N. Shetty, Corros. Sci., 2011, 53, 3688-3696.

5. M. El Faydy, B. Lakhrissi, C. Jama, A. Zarrouk, L. O. Olasunkanmi, E.E. Ebenso, F. Bentiss, J. Mat. Res. Technol., 2020; 9(1), 727-748

6. Lin Wang, Corros. Sci., 2006, 48, 608-616.

7. M.E. Belghiti, Y. Karzazi, A. Dafali, I.B. Obot, E.E. Ebenso, K.M. Emrane, I. Bahadur, B. Hammouti, F. Bentiss, J. Mol. Liq., 2016, 216, 874-886.

8. M.A. Hegazy, J. Mol. Liq., 2015, 208, 227-236.

9. A. Ghanbari, M.M. Attar, M. Mahdavian, Mater. Chem. Phys., 2010, 124, $1205-$ 1209.

10. X. Li, S. Deng, H. Fu, Corros. Sci., 2011, 53, 664-670.

11. M.S. Al-Otaibi, A.M. Al-Mayouf, M. Khan, A.A. Mousa, S.A. Al-Mazroa, H.Z. Alkhathlan, Arab. J. Chem., 2014, 7, 340-346.

12. M. Boudalia, R.M. Fernández-Domene, M. Tabyaoui, A. Bellaouchou, A. Guenbour, J. García-Antón, J. Mater. Res. Technol. 2019, 8(6), 5763-5773.

13. A. S. Yaro, A. A. Khadom, R. K. Wael, Alex. Eng. J., 2013, 52, 129-135.

14. M. Messali, H. Lgaz, R. Dassanayake, R. Salghi, S. Jodeh, N. Abidi, O. Hamed, J. Mol. Struct., 2017, 1145, 43-54.

15. M. Özcan, İ. Dehri, M. Erbil, Appl. Surf. Sci., 2004, 236, 155-164.

16. E. Barsoukov, J.R. Macdonald, Impedance spectroscopy: Theory, Experiment, and Applications, second ed. John Wiley \& Sons, New Jersey, 2005.

17. C. Cao, Corros. Sci., 1996, 38, 2073-2082. 